OPEN ACCESS

Edited by:

Waqar Ahmad,

University of Queensland, Australia

Reviewed by:

Sahib Alam,

University of Agriculture,

Peshawar, Pakistan

Muhammad Sabir,

University of Agriculture,

Faisalabad, Pakistan

*Correspondence:

Mandy Hinzmann

mandy.hinzmann@ecologic.eu

Specialty section:

This article was submitted to

Plant-Soil Interactions,

a section of the journal

Frontiers in Agronomy

Received: 29 January 2021 Accepted: 17 March 2021

Published: 16 April 2021

Citation:

Hinzmann M, Ittner S, Kiresiewa Z and Gerdes H (2021) An Acceptance Analysis of Subsoil Amelioration Amongst Agricultural Actors in Two Regions in Germany.

Front. Agron. 3:660593.

doi: 10.3389/fagro.2021.660593

\section{An Acceptance Analysis of Subsoil Amelioration Amongst Agricultural Actors in Two Regions in Germany}

\author{
Mandy Hinzmann *, Sophie Ittner, Zoritza Kiresiewa and Holger Gerdes \\ Ecologic Institute, Berlin, Germany
}

The subsoil, commonly defined as horizons below the working depth of $30 \mathrm{~cm}$, often receives little attention in farming practice. Yet plants extract between 10 and $80 \%$ of their nutrient and water requirements from the subsoil. Recent research indicates that subsoil amelioration measures, which enhance water storage capacity, root penetration and microbial activity, could contribute to stabilizing yields in times of drought. Therefore, we investigated farmers' and other soil experts' perceptions of subsoil amelioration as an approach to adapt to climate change as well as the factors that influence their willingness to adopt specific measures to improve the subsoil. We applied the Q-method combined with focus groups in two case study regions in Germany. Two subsoil amelioration techniques were considered: (1) Deep loosening combined with the incorporation of compost into deep soil layers $(30-60 \mathrm{~cm}$ ) and (2) the cultivation of alfalfa as deep-rooting pre-crop. Our results show three distinct views on subsoil amelioration, which we termed as the "pioneers," the "skeptics," and the "ecologists." While the pioneers were open toward applying deep loosening combined with incorporation of compost into the subsoil, the skeptics had concerns about the method and perceived it as hardly feasible in practice, and the ecologists clearly preferred biological approaches such as alfalfa cultivation. Despite the different views, all three perspectives view subsoil amelioration as a useful approach to adapt to changing climate conditions. In conclusion, we identified a number of factors that influence the willingness to implement specific techniques to improve the subsoil: economic and farm-level considerations, awareness of subsoil functions, environmental awareness, individual norms and beliefs as well as risk perception. We recommend considering these factors in the design of a policy framework that promotes subsoil amelioration in Germany. Our findings could be of relevance for agricultural systems around the world, which are prone to drought risk.

Keywords: subsoil, soil amelioration, drought, climate change adaptation, compost, alfalfa, acceptance, Q-method

\section{INTRODUCTION}

The effects of climate change are vast, including increases in the frequency, intensity, and duration of weather extremes. These impacts in turn increase the degree of pressure and impacts on land in Europe and globally (IPCC, 2019). In the past few years, extensive droughts have particularly affected the agricultural sector in Europe. Due to extremely low rainfalls in combination with 
high temperatures, for instance, Northern and Eastern Europe experienced multiple and high crop failures in 2018 (Beillouin et al., 2020). Projections based on high emission scenarios (e.g., Representative Concentration Pathways, RCP 8.5) show that Central Europe and the Mediterranean will be particularly affected by more intense and frequent droughts (Spinoni et al., 2018; IPCC, 2019; Toreti et al., 2019). Climate change affects agricultural productivity and leads to reduced stability of food supplies and thus decreasing food security. There is an urgent need for sustainable intensification and adaptation strategies for European agriculture to face these and related future challenges (Grillakis, 2019; Toreti et al., 2019).

Farmers need to adapt their management to changing climate conditions and increase yields in a sustainable way. In addition to the cultivation of plants better adapted to drought conditions, one possible strategy could be to use available resources more effectively. Funded by the German Federal Ministry of Education and Research, the long-term research project Soil ${ }^{3}$ (see https:// www.soil3.de) has been designed to help farmers to adapt to climate change and enhance productivity by including subsoil into sustainable agricultural management strategies. The project aims to optimize nutrient and water uptake from the subsoil by crops as a means to stabilize or even increase yields under unfavorable climatic conditions.

Many studies in recent years have shown that the subsoil can hold immense reservoirs of nutrients and water and may contribute between $10 \%$ to more than $80 \%$ to plant nutrition (Gaiser et al., 2012; Kautz et al., 2013; Lynch and Wojciechowski, 2015; Schneider and Don, 2019a,b). Subsoil here is defined as the soil layers $\sim 30 \mathrm{~cm}$ beneath the tilled soil horizon. Especially under poor growing conditions such as depleted topsoils and droughts, these subsoil reserves can be an important back-up to sustain and stabilize yields (Gaiser et al., 2012; Kautz et al., 2013; Lynch and Wojciechowski, 2015). However, Schneider and Don (2019a) demonstrate that in Germany, for example, over $70 \%$ of soils show root restrictions in $<100 \mathrm{~cm}$ depth, mostly due to compacted soil layers. Consequently, these resources often remain inaccessible to plants, which can have negative effects on productivity.

There are various mechanical and biological methods that help overcome such compacted soil layers, facilitate root growth into deeper layers (Schneider and Don, 2019b) and thus support the uptake of nutrients and water from the subsoil-and thereby increase yields (Gaiser et al., 2012; Cai et al., 2014; Landl et al., 2019; Sale et al., 2019; Seidel et al., 2019). Biological methods are based on the effect of the cultivation of deep-rooted precrops (e.g., alfalfa) and the formation of biopores down into the subsoil (bio-drilling) (Kautz et al., 2014; Landl et al., 2019; Seidel et al., 2019). Mechanical methods encompass for example deep loosening (subsoiling) to break up compacted layers (FrelihLarsen et al., 2018).

It has long been assumed that farmers' decision-making is driven primarily by economic interests. However, studies show that farmers' soil management is influenced by more than economic considerations and depends on mental models linking perceptions, attitudes, and beliefs with behavior (Prager and Curfs, 2016; Frelih-Larsen et al., 2018; Marr and Howley, 2019;
Braito et al., 2020). Acceptance depends on the willingness and ability of farmers to adopt management practices (Mills et al., 2017; Frelih-Larsen et al., 2018). Dessart et al. (2019) provide an overview of behavioral factors that influence farmers' decisions to adopt environmentally sustainable practices in Europe based on a review of findings from the last 20 years. Frelih-Larsen et al. (2018) show that, in addition to economic considerations, biophysical conditions, the timing of operations and awareness of subsoil functions are key factors in the acceptance of subsoil amelioration methods in Germany.

The acceptance of agricultural measures by farmers and other societal actors is essential for a far-reaching and sustainable implementation of (new) measures in agricultural practice. It is necessary to have a systematic, in-depth understanding of the factors influencing the willingness and ability to integrate the complex nature of farmers' decision-making into policy design (Mills et al., 2017; Bartkowski and Bartke, 2018; FrelihLarsen et al., 2018; Helming et al., 2018). Given this background, this paper evaluates the individual viewpoints of farmers and other relevant stakeholders regarding the implementation of alternative subsoil amelioration techniques by applying the Qmethod in two case study regions in Germany. Specifically, we investigate whether agricultural actors see subsoil amelioration as a useful approach to adapt to climate change, which factors influence the acceptance of specific techniques to improve the subsoil, and how policy-makers and agricultural consultancies could support the implementation of sustainable subsoil amelioration in Germany.

\section{METHODOLOGY \\ Object of Research: Subsoil Amelioration Techniques}

In the frame of the present acceptance analysis, the focus was on two alternative subsoil amelioration techniques. The first presents a biological approach to subsoil amelioration, the second a mechanical approach. Both techniques can be combined.

\section{Alfalfa Cultivation}

One opportunity for roots to overcome compacted soil layers is the use of large-sized biopores formed by tap-rooting plants or earthworms as preferential growth pathways (Kautz et al., 2014; Landl et al., 2019; Huang et al., 2020). Biopores are hotspots with particularly high organic matter, microbial activity and nutrient availability (Kautz et al., 2014; Kuzyakov and Blagodatskaya, 2015), which enhance water infiltration and have a proven beneficial impact on root water uptake in times of drought (Gaiser et al., 2012; Landl et al., 2019). These biopores can remain in the subsoil over years (Hagedorn and Bundt, 2002). Examples for deep-rooting pre- or intercrops with mechanically resilient root systems, which are able to penetrate compacted subsoil layers (Yunusa and Newton, 2003; Gill et al., 2008; Gaiser et al., 2012; Huang et al., 2020), include alfalfa, clover, chicory and lupine. In the present study, we investigated alfalfa cultivation as exemplary technique to biologically ameliorate the subsoil. Alfalfa develops both a strong taproot that is able to reach deep soil layers, and multiple branches that create a broad root 


\section{Amelioration technology}


FIGURE 1 | Mechanical subsoil amelioration: the five steps of the Soil ${ }^{3}$ method. (c) Oliver Schmittmann.

network. Alfalfa plants need to remain on the field for $\sim 1-2$ years to form biopores that have an effect on the main crops.

\section{Deep Loosening With Incorporation of Compost (DLC)}

The Soil ${ }^{3}$ project runs three central field experiments, designed for development, and testing of different techniques of subsoil amelioration, namely stripwise subsoil loosening with and without incorporation of organic material, e.g., biowaste compost (Jakobs et al., 2019). Within the research project, a machine (subsoiler) has been developed, which facilitates the stripwise loosening of the subsoil with simultaneous incorporation of organic matter in depths between 30 and $60 \mathrm{~cm}$ without mixing the $\mathrm{A}$ and $\mathrm{B}$ horizons. It includes the following steps (see Figure 1): (1) uncovering of the A horizon, (2) deposing of organic material in the opened furrow, (3) mixing of the organic material and the $\mathrm{B}$ horizon, (4) re-compaction of the $\mathrm{B}$ horizon, and (5) re-establishment of the A horizon. The furrow width in the field experiments was $30 \mathrm{~cm}$, with distances between the furrows of $70 \mathrm{~cm}$. The design of the machine allows adapting these widths as well as the working depth to suit local field conditions.

The technique may enhance the subsoil's ability to store water (Zhang et al., 2005; Leskiw et al., 2012) and facilitate improved water uptake from the subsoil (Gill et al., 2008). Data from the project's central field experiments show that mechanical subsoil loosening with the incorporation of compost has resulted in an increase in yield of between 19 and $36 \%$ on average in three consecutive years $(2017,2018$, and 2019) (Jakobs et al., 2019; Ittner et al., 2020).

\section{Q-Method}

The Q-method is an empirical, exploratory, participatory method within the social sciences and combines qualitative and quantitative research approaches (Watts and Stenner, 2005; Webler et al., 2009). It aims to explore subjective values, perspectives, and attitudes on a particular topic. Social acceptance is strongly influenced by subjective beliefs (Sattler and Nagel, 2010; Prager and Curfs, 2016; Mills et al., 2017; Frelih-Larsen et al., 2018), which is why the Q-method is particularly suitable for research on acceptance. Thus, the Q-method has already been used in a large number of acceptance studies (Ellis et al., 2007; Bumbudsanpharoke et al., 2009; Cools et al., 2012; Curry et al., 2013; Byrne et al., 2017; Braito et al., 2020). The great advantage of the Q-method is the consideration of the relationships between all variables, instead of the isolated analysis of individual aspects of a topic. As a result, this method is well-suited to identify subjective points of view on complex issues and makes it possible to identify complex opinion structures (Stainton Roger, 1995; Watts and Stenner, 2005).

\section{Development of the Q-Set}

For this study, we developed a set of 27 statements which reflect different views on subsoil amelioration using a "naturalistic sample" (Müller and Kals, 2004). We drew the statements from interviews with farmers and other soil experts (agricultural consultancy, science, civil society, and policy) in Germany. We applied this approach, as the perception of subsoil amelioration is largely unexplored and other sources such as scientific literature, newspaper articles or ready-to-use statements on the topic were not available. The main objective of the Q-set is to be broadly representative and reflect all different aspects of a specific topic (Watts and Stenner, 2005). Therefore, special attention was paid to ensuring that the selection of the 27 statements covered a wide range of different factors that may determine the uptake of subsoil amelioration measures. These acceptance factors were identified and adapted on the basis of Frelih-Larsen et al. (2018). Despite the fact that the interviews provided a variety of interesting aspects with regard to the implementation and possible impacts of both DLC and biological measures, the Qset is slightly dominated by statements on DLC. In comparison, the statements on biological measures were discussed with less controversy and focused on similar issues across all interviews. That is why fewer statements cover all different viewpoints expressed by the interviewees. Table 1 shows how the selected statements correspond to the categories of acceptance factors.

\section{Sampling of the Q-Sorts}

The acceptance analysis was implemented in two case study regions: (a) Western Germany (North Rhine-Westphalia) and (b) North-East Germany (Mecklenburg-Western Pomerania and 
TABLE 1 | Q-set and corresponding acceptance factors.

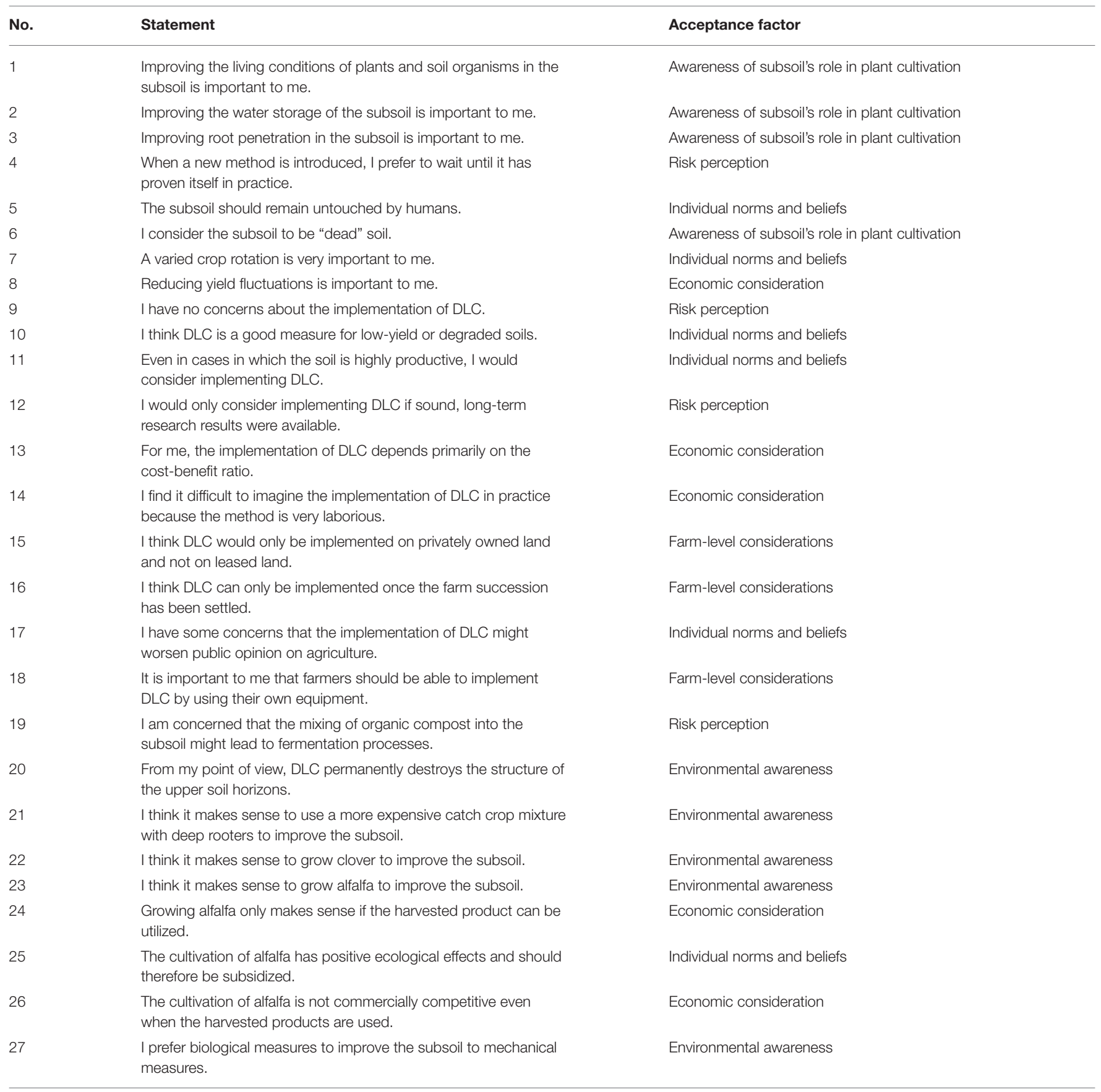

Brandenburg). In principle, both regions have favorable geophysical conditions for subsoil amelioration techniques-e.g., soil depth and presence of rock fragments (Frelih-Larsen et al., 2018; see Schneider and Don, 2019a). On the other hand, the two regions differ in ecological and socio-economic criteria such as climate, soil type and quality, degree of soil compaction, farm size, and land tenure. This makes it interesting to analyze them comparatively. To ensure that we cover a variety of perspectives on subsoil amelioration, as recommended in the literature (Watts and Stenner, 2005; Kamal et al., 2014), our sample included a wide range of soil experts with different backgrounds (agriculture consultancy, science, civil society and policy) as well as farmers whose farms display different characteristics (e.g., production systems, farm size, soil types; see Table 3 ). In total, we conducted interviews with 50 farmers and 36 other soil experts across the case study regions.

The participants were contacted through agricultural advisors and by using snowball sampling. We used different data collection methods such as physical and online workshops combined with focus group discussions, as well as face-to-face 


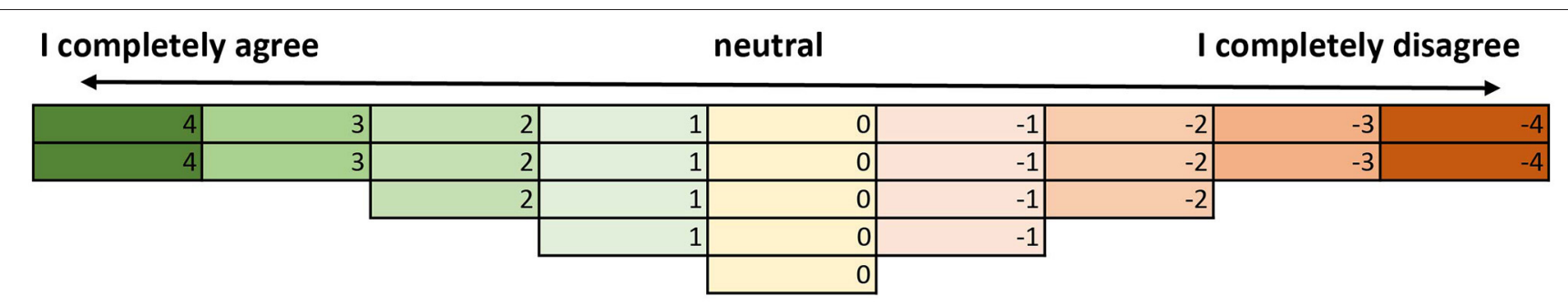

FIGURE 2 | Ranking scale for the Q-method.

and online interviews. Irrespective of the selected data collection methods, all formats followed the same structure. First, we shortly introduced the investigated measures (DLC and the biological measures), creating a comparable starting position for all respondents. Afterwards, each participant individually assigned the statements in a ranking scale (see Figure 2) according to their level of (dis)agreement (Q-sort). In our study, the scores of statements ranged from -4 to +4 , with -4 meaning strong disagreement and +4 strong agreement. Scores around zero mean that the participants were indifferent to the statement (Brown, 1980).

In the focus group and individual interviews following the Q-sorting exercise, the highest and lowest rankings were first discussed to reveal the reasoning behind the decision of each respondent. The following discussion focused on potential obstacles and motivation factors toward the implementation of subsoil amelioration measures. This information supported the interpretation of the different perspectives.

\section{Data Analysis}

A statistical factor analysis of all collected Q-sorts was performed in order to identify groups of participants who have put the statements in a similar order. More specifically, we conduct a principal component analysis (PCA) using a Varimax rotation. The digitalized Q-sorts were analyzed using the web application Ken-Q Analysis (https://shawnbanasick.github.io/ ken-q-analysis/). Within the analysis, a large number of factors are created. To select a relevant number of meaningful factors, according to Brown (1980), factors should fulfill the following criteria: (a) the eigenvalues should be $>1$ (eigenvalue criterion) and (b) each factor should be defined by at least two significant loadings (Q-sorts) in the unrotated factor matrix (significance criterion). Based on these two criteria, we have chosen a threefactor solution. The individual Q-sorts were assigned to the three factors according to the correlation $(p<0.05)$ between participants and factors (loadings). If a Q-sort significantly loaded on several factors, participants were not considered in the following analysis. As a result, factors are extracted which represent different perspectives ("typical views of a group") and which are characterized by a calculated "average" sorting of the statements (Z-scores; see Figure 3). Together with the transcribed interviews and focus group discussions, these ideal typical Q-sorts serve as a basis for the descriptive narrative of each perspective.

\section{RESULTS}

\section{Description of the Sample}

Overall, 50 farmers and 36 other soil experts were included in the survey, with $63 \%$ of the respondents coming from case study region 1 and $37 \%$ from case study region 2 . In total, 71 of the 86 Q-sorts could be assigned significantly to one of the three identified perspectives. The three factors in total explain $62 \%$ of the variance (see Table 2 ).

Table 3 shows the distribution of the participants across the three perspectives and the associated affiliation to the regions and farm-level characteristics. A total of 39 participants share similar views on subsoil amelioration and have been assigned to perspective 1 , which is the largest group. Twenty-five of the group members are farmers and 14 are soil experts with an approximately equal regional spread between the two case study regions North Rhine-Westphalia (43\%) and MecklenburgWestern Pomerania \& Brandenburg (53\%). The vast majority of the farmers (80\%) practice conventional arable farming; only seven farmers are oriented toward organic farming. Most farmers of this group already experienced problems with harmful compaction in the subsoil and have experiences with deep loosening.

Almost 20\% (16 persons) of the participants were assigned to the second perspective. Most of them were soil experts and stem from region 2 (Mecklenburg-Western Pomerania \& Brandenburg). Out of the five farmers in the group, the majority engages in mixed farming.

Similar to perspective 2, perspective 3 is also characterized by the view of 16 participants on subsoil amelioration. In contrast to perspective 2, however, most of the people assigned to perspective 3 come from region 1 (North Rhine-Westphalia). This group consists mainly of farmers (10 persons) who are engaged in mixed and livestock farming. The group is divided equally between farmers who practice conventional farming and farmers who practice organic farming. Most of them have not yet had any problems with harmful compaction in the subsoil.

\section{Different Views on Subsoil Amelioration Techniques}

The results of the acceptance analysis show three distinct perspectives on subsoil amelioration, which we named as the "pioneers," the "skeptics," and the "ecologists." Figure 3 below shows the ranking of the statements across the three perspectives. 


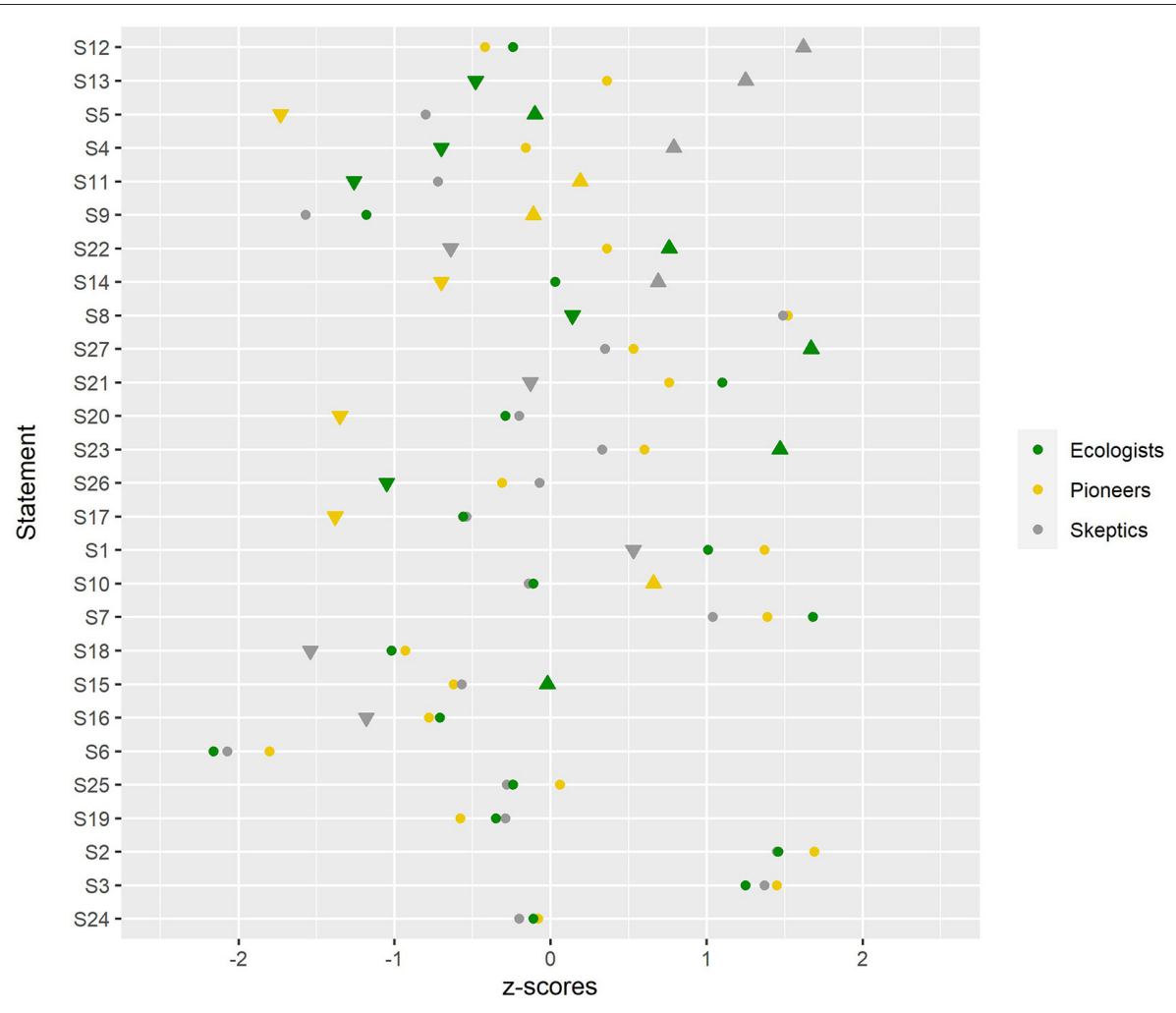

FIGURE 3 | Ranking of statements from most controversial (Top) to least controversial (Bottom). Triangle symbols highlight distinguishing statements with a significance at $P<0.01$ and where the Z-scores for the statement is higher $(\mathbf{\Lambda})$ or lower $(\boldsymbol{\nabla})$ than for all other factors.

TABLE 2 | Overview of explained variance and number of loadings.

\begin{tabular}{lcccc}
\hline & Full sample & Factor 1 & Factor 2 & Factor 3 \\
\hline Percentage of explained variance & $62 \%$ & $27 \%$ & $17 \%$ & $18 \%$ \\
$\begin{array}{l}\text { Number of significantly Loadings } \\
\text { (Q-sorts) }\end{array}$ & $71(83 \%)$ & $39(45 \%)$ & $16(19 \%)$ & $16(19 \%)$ \\
\hline
\end{tabular}

\section{Perspective 1-The "Pioneers"}

The "pioneers" are open to the implementation of DLC and perceive it as a good measure for low-yield or degraded soils (S10). This is supported by the fact that, in contrast to the other two perspectives, the group shows a slight tendency to implement DLC even in the case of the soil being highly productive (S11). Alongside the acceptance of mechanical subsoiling, the members of the group are in favor of biologically intervening in subsoils, in particular with the cultivation of clover (S22). Moreover, the respondents in this perspective endorse the positive ecological effects of alfalfa, which is mainly based on personal experience with alfalfa cultivation, while stressing the need for subsidies (S25). This is reinforced by the statement: "I believe agriculture has to pursue the societal objective toward landscape conservation and this should be honored and promoted" (soil expert 51).

Respondents in this group perceive the implementation of DLC with few reservations, which is demonstrated particularly by the high ranked statement "I have no concerns about the implementation of DLC" (S9). The statement that the implementation of DLC could worsen the public opinion about agriculture (S17) is marked by a very low acceptance. One of the reasons given is that the expected positive impact of DLC on soil carbon sequestration is very likely to create societal support for the measure and as such DLC should be framed in this context. In addition, the "pioneers" do not perceive DLC as a complex method, which is difficult to implement in practice (S14) as the common practice in Germany is to commission contractors for measures requiring the use of specific machinery that is not regularly needed on the farm. In this group, there also is no concern that DLC could destroy the structure of the upper soil horizons (S20). In this regard, farmer 26 stated: "I think other measures are much worse. It also depends on what kind of soil I have and how I cultivate it in general. I wouldn't judge that by one measure." While the "skeptics" also reject the statement that the subsoil should remain untouched by humans (S5), the rejection in this group is significantly higher. There is a high degree of agreement that the subsoil must be used and improved, not least because "it is already manipulated by the plant roots in crop production" (farmer 21). The members of the group argue that a nature-compatible treatment of the subsoil is sometimes necessary for environmental reasons to prevent $\mathrm{N}$ to end up in the groundwater, or to improve the water storage capacity for flood protection. They also consider subsoil tillage necessary, 
TABLE 3 | Description of factors.

Full sample Factor 1 Factor 2 Factor 3

\section{Per region}

Region 1

Region 2

Stakeholder group

Soil experts

Farmers

Farm type

Mainly arable farming

Mainly livestock farming

Mixed farming

Farm size

$<50$ ha

51-250 ha

251-1,000 ha

More than 1,000

Share of owned area

Farming system

Organic farming

Conventional farming

Already experienced problems with harmful compaction in the subsoil

Yes

No

$30(60 \%)$

$12(24 \%)$

16

7

$8(16 \%)$

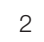

2

8

0

Unknown

$29(58 \%)$
$19(38 \%)$
$3(6 \%)$

Unknown

Farm succession

Yes

No

\section{$36(72 \%)$}

$13(26 \%)$
3

1

8

2

especially if the aim is to increase yields and ensure global food security. In this case, the subsoil should be considered as a production factor as it could play a significant role in achieving this aim. This also applies when the soil is compacted.

\section{Perspective 2-The "Skeptics"}

Respondents in this perspective express skepticism about mixing compost into the subsoil. In their view, it is of utmost importance that, before adopting such a technique, reliable research results that encompass long-term effects are available (S12). Additionally, respondents in this group generally tend to wait with the adoption of a new farming technique until it has proven itself in practice (S4). Farmer 93 epitomized this waitand-see-attitude by stating that before applying DLC on his land, he would first test the technique on a small test site, "so that you can see it for yourself at the location."

Of the three groups, the "skeptics" most strongly expressed concerns about the DLC technique (S9). They voiced specific concerns ranging from the regional availability of high-quality compost, to an increased risk of re-compaction and nitrogen

pollution. In addition, respondents in this group strongly criticized the fact that testing the effectiveness of DLC in the frame of the Soil ${ }^{3}$ project did not include a control plot in which the same amount of compost was distributed on the topsoil. As a result, according to some of the respondents, it remains uncertain whether the achieved yield increases in the field trial present a mere fertilization effect-which farmers could achieve with much less complex and costly approaches. In general, the skeptics see a need for further rigorous testing of the DLC approach.

Compared to the other groups, the skeptics care most about the cost-benefit ratio of DLC (S13). Here, respondents emphasized that many farmers are currently under a general cost pressure, and therefore need to plan their investments carefully. For example, soil expert 54 clearly stated: "Why else would the farmer do this? At the moment, they are all struggling anyway. So the technique will not be accepted if the farmer does not expect any monetary benefit from it." Similarly, farmer 33 explained: "The cost-benefit ratio is very important because it is terribly difficult in agriculture to generate proper revenues, because the prices for the products are very bad and we cannot come up with... with considerable costs, additional costs and say that this [DLC] is good for you. First of all, it really has to be proven that it is good." The farmer's quote reveals that the high importance of the cost-benefit ratio (S13) and the request of reliable research results (S12) are interlinked. In line with this, farmers in this group emphasized that they are unwilling to bear the risk of such an expensive measure, unless solid research results are available first.

Furthermore, respondents in this group perceive DLC as a laborious technique, which they see as an obstacle for implementation (S14). They describe it as a rather costly, time-consuming and complex technique and were overall not yet convinced that applying DLC was profitable. Farmer 92 illustrated this perspective, stating: "For me as a farmer, I see problems there. That is a bit too much work for me. I find it interesting, especially for horticulture. But at the moment I find it hard to imagine that it makes economic sense in largescale cultivation."

\section{Perspective 3-The "Ecologists"}

Respondents assigned to this perspective strongly prefer biological measures to improving the subsoil over mechanical measures (S27). Consequently, respondents see the cultivation of alfalfa (S23), the use of more expensive intercrop mixtures (S21), and the cultivation of clover (S22) as sensible measures to improve the subsoil. Compared to the other groups, the "ecologists" care most about a varied crop rotation (S7).

At the same time, respondents in this perspective strongly reject implementing DLC on highly productive soils (S11), as they are unwilling to risk soil quality and functionality. In line with this, they express concerns about implementing DLC (S9). As an illustration, farmer 12 describes DLC as "a major intervention in the soil. The topsoil is removed or moved to the side, the soil intervention is relatively strong and I believe that in the long run, you can achieve more with biological measures such as catch crops, a reasonable crop rotation and also organic fertilizer." 
For the ecologists in general, mechanical measures such as deep loosening or DLC present a risk for the soil. Specifically, respondents are concerned about damaging the soil structure and increasing the risk of (re-)compaction. This is illustrated particularly well by a statement made by farmer 78: "I am convinced that you can achieve as much with biological measures as with mechanical ones, but without taking risks for the soil." Yet, respondents in this perspective are not risk-averse in principle, as they do not prefer to wait until a newly introduced technique has proven itself in practice (S4).

In contrast to the other two perspectives, for the ecologists, the implementation of DLC does not primarily depend on the cost-benefit ratio (S13). Yet-similar to the "skeptics"they find it difficult to imagine the implementation of DLC in practice, as they consider the measure to be very laborious (S14). Interestingly, of the three perspectives the ecologists are the only ones that believe that DLC would be implemented on privately owned land rather than on leased land (S15). One respondent argued that many property owners were opposed to implementing compost or sewage sludge due to concerns about pollutants. In this case, it would be difficult to get the property owner to agree to DLC. Others argued that lease contracts are often very short, so that it does not make sense to invest in an expensive technique.

Next, respondents see mechanical measures to improve the subsoil as short-term solutions with little long-term effectiveness. In contrast, they emphasize the multiple long-term benefits of biological approaches on soil biota, biological diversity, soil structure and resilience, humus formation, and availability of nutrients. Against this background, the ecologists find it acceptable that biological approaches need time to take effect. This is reflected by their willingness to cultivate alfalfa or similar pre-crops which need to stay on the field for about 2 years to form effective biopores. As farmer 61 expressed it: "You can easily see when you grow alfalfa how many advantages it can have in the subsoil. And how easy it actually is."

Respondents in this perspective strongly reject the statement that cultivating alfalfa is not commercially competitive (S26). In fact, various farmers who agree with this perspective are cultivating alfalfa and have positive experiences with it.

\section{Shared Beliefs and Values}

We found that despite the different views across the three groups, a number of statements were evaluated in a similar way. This indicates that respondents share a number of beliefs and values regarding the subsoil's role in agriculture and in regard to specific subsoil amelioration techniques.

Two statements received particularly high positive ratings, indicating a strong consensus among the respondents: improving root penetration (S3) and water storage (S2) of the subsoil are seen as being important. Respondents also emphasized the interrelation between the two statements.

One statement received particularly negative ratings: Respondents in all three groups strongly disagreed with the notion that subsoil was "dead soil" (S6).

Moreover, farmers and other soil experts generally acknowledged the importance of a varied crop rotation
(S7). Regarding the DLC technique, respondents showed no concern about potential fermentation processes in the subsoil due to compost incorporation (S19). Farmers and other soil experts agreed that for the implementation of DLC it is neither necessary that the farm succession is settled (S16) nor that farmers are able to use their own equipment (S18).

\section{DISCUSSION}

\section{Subsoil Amelioration as a Useful Strategy to Adapt to Climate Change}

Our research results indicate that farmers as well as other soil experts in the two case study regions see subsoil amelioration in general as a very valuable approach to adapt to climate change. The strong consensus on statement 2 shows that the overall most important motivation to consider subsoil amelioration was to improve the water storage of the subsoil. Studies indicate that climate change will increase existing risks like water shortages and floods in Europe with regional differences, which will have an impact on regional agricultural production and yields (Bindi and Olesen, 2011; Iglesias et al., 2012; Iglesias and Garrote, 2015; Spinoni et al., 2018; Agovino et al., 2019; IPCC, 2019; Toreti et al., 2019). In the interviews and focus group discussions, many farmers and farm advisors reported that in recent years their region, and often their own businesses, have been severely affected by droughts and by subsequent yield declines. Personal experience of climate change as well as concerns and perception about climate change have been shown to increase farmers' willingness to adapt their management (Woods et al., 2017; Ricart et al., 2018; Hasan and Kumar, 2019; Mitter et al., 2019). This is in line with our findings: The interviewed participants emphasized the urgent need to find strategies in the agricultural sector to deal with the changing climatic conditions. Beside the adaptation of crop management, such as the cultivation of drought resistant crops, irrigation is one approach to adapt to dry periods (Howden et al., 2007; Iglesias et al., 2011). It is likely that the extent of irrigation will increase in Germany and Central Europe (Elliott et al., 2014; Riediger et al., 2014). This requires larger investments where irrigation equipment does not yet exist. Besides, water resources for irrigation are not unlimited (Elliott et al., 2014), which is why further adaptation strategies should be pursued. Our study shows that increasing the subsoil's capacity to store water was seen as a good strategy to better bridge temporary extreme deficits. Increasing the water-holding capacity of soils, e.g., by increasing the organic matter content, provides a better supply of water to the plant, reduces the need for irrigation and is thus an additional good option for adapting to drought conditions (Iglesias et al., 2011; Williams et al., 2016). Apart from mitigating droughts, respondents mentioned that subsoil amelioration could enable a better infiltration and percolation of water in the soil-and thereby help prevent water erosion in the case of heavy rainfall events. In fact, improving soil drainage to reduce waterlogging, e.g., through improving soil structure and adapted plowing management, is seen as an effective measure to reduce the risk of floods (Howden et al., 2007; Iglesias et al., 2011; Iglesias and Garrote, 2015). 


\section{Factors to Enhance the Acceptance of Subsoil Amelioration}

While acceptance for the concept of subsoil amelioration is high among the respondents of our study, the acceptance of the two specific subsoil amelioration techniques varies among the three identified perspectives. The Q-method revealed that different sets of factors influence the acceptance in each perspective. In the following, we highlight interesting findings from each perspective and discuss which conclusions can be drawn for promoting subsoil amelioration measures. The acceptance of subsoil amelioration among farmers and other relevant soil experts is a topic that so far has scarcely been discussed in the literature. Therefore, we draw on published literature on the broader topic of acceptance and willingness to implement sustainable soil management to discuss our findings. For a systematic approach, the discussion follows the acceptance factor categories outlined in Table 1.

\section{Awareness of Subsoil's Role in Plant Cultivation}

We can deduce that the respondents in our sample generally acknowledge the subsoil's potential to contribute to healthy soils and plant supply. This finding is substantiated by the clear consensus among the respondents that subsoil is not to be considered as "dead soil." Thus, we find a distinct awareness of subsoil functions among the interviewed farmers and other soil experts. Moreover, in all three perspectives, respondents recognized the interlinkage between water storage capacity, root penetration, and activation of soil life in the subsoil. They highlighted it as positive that sustainable subsoil amelioration strategies address all these aspects. This is in line with PetrescuMag et al. (2020), who have shown that farmers perceive soil functions that ensure productivity and support beneficial microorganisms as most important, as well as with findings that farmers in Europe overall have a good understanding of soil functions and soil quality (Bampa et al., 2019; Petrescu-Mag et al., 2020).

In part, the high degree of awareness regarding subsoil functions could be attributed to a bias in the sample of respondents. Despite our careful efforts to cover a wide range of actors and perspectives in our sample, we need to take into account that those stakeholders, who are well-educated, well-informed, and who maintain close contact to agricultural advisories are particularly likely to participate in surveys. Nevertheless, the Q-method is ideally suited to reveal minority views in the sample (Brown, 2006) and therefore it is an important finding that in all three identified perspectives, respondents regarded the subsoil's functions as relevant. Even in the more doubtful perspective of the "skeptics," improving water storage as well as root penetration in the subsoil is seen as relevant.

\section{Environmental Awareness}

Environmental awareness has a strong influence on the acceptance of subsoil amelioration techniques among the "ecologists." Ecological benefits can present a greater motivation for them to implement measures than economic benefits, such as increased yields. In particular, expected positive long-term effects on soil functions motivate the "ecologists" to implement measures such as cultivating deep-rooting pre-crops, while the long-term benefit of mechanical measures is doubted by the "ecologists". Cranfield et al. (2010) made a similar observation when researching motives of conventional farmers to convert to organic farming. The authors found that environmental considerations-next to health and safety concerns-played a more important role than economic consideration. In the other two perspectives, respondents show less readiness to implement measures based on their environmental benefits; expected economic benefits represent a significantly greater motivation.

Interestingly, the farmers associated with the perspective of the ecologists in our study are not all organic farmers, indicating that a number of conventional farmers take on this perspective. Furthermore, not all organic farmers among our respondents are assigned to this group; some take the perspective of the "pioneers" or "skeptics." Therefore, the preference for biological approaches cannot be directly linked to organic farming, whereas earlier findings suggest that farmers with environment-conscious attitude are more likely to be engaged in organic farming (Fairweather, 1999; Cranfield et al., 2010). More generally, there is a public discourse on the impact of land use on resources such as water, soil, climate, and biodiversity e.g., through the discussion on the need to better align the European Union's Common Agriculture Policy (CAP) with sustainability objectives (Pe'er et al., 2019, 2020). The regular survey of EU citizens, which explores public opinion about agriculture, rural areas and the CAP, shows that in addition to providing safe and healthy food of high quality, one third of respondents believe that protecting the environment and tackling climate change are among the two most important tasks of farmers (European Commission, 2020). Societal pressure on farmers is growing, which can have an impact on their environmental awareness and, consequently, on their decision-making (Bartkowski and Bartke, 2018; Dessart et al., 2019).

The respondents emphasized the possibility of contributing to increased carbon storage and thus to climate change mitigation through subsoil amelioration. The introduction of $\mathrm{CO}_{2}$ certificates in agriculture, which is increasingly discussed in Germany (Hermann et al., 2017; Jacobs et al., 2020) and Europe (Eory et al., 2018; Cevallos et al., 2019; Leinonen et al., 2019), could represent an additional incentive to implement such measures, whereby the permanence of the sequestered carbon in soils needs to be ensured (Wiesmeier et al., 2020).

\section{Risk Perception}

Risk perception of farmers has been intensely researched (Flaten et al., 2005; Trujillo-Barrera et al., 2016; Dessart et al., 2019; Duong et al., 2019; Sulewski et al., 2020). It is well-known that the willingness to take risks is closely linked to economic aspects, but also to personality (Ghadim et al., 2005; Prager and Posthumus, 2010; Dessart et al., 2019; Sulewski et al., 2020). This is mirrored in our results: the personal risk perception varies between the three identified perspectives and is influenced by economic considerations. While both the "pioneers" and "ecologists" demonstrate willingness to take certain risks, the group of "skeptics" is markedly risk-averse. At the same time, 
a positive cost-benefit ratio of subsoil amelioration techniques is essential for them. Particularly for this group, a targeted financial support for the first-time cultivation of alfalfa or application of DLC can cushion the risk for farm businesses and could thus help overcoming an important obstacle. In addition, skeptics expressed their unwillingness to adopt specific subsoil amelioration measures, in particular the DLC technique, as in their view the current information base does not yet allow for an adequate risk assessment. Similarly, Duong et al. (2019) found that for farmers around the globe, lacking access to information is an important barrier for risk management. Providing information regarding the effectiveness and sideeffects of specific subsoil amelioration techniques seems to play an important role and should be taken up in future research (compare section Options to Enhance Acceptance for the DLC Technique) and addressed in targeted communication strategies that aim at promoting subsoil amelioration.

\section{Individual Norms and Beliefs}

Individual norms and beliefs are closely related to moral attitudes and are often influenced by societal views. Furthermore, moral concerns may influence farmers' behavior (Bartkowski and Bartke, 2018; Dessart et al., 2019). As factors like social capital, social norms and peer orientation are difficult to capture, these factors are studied relatively rarely (Bartkowski and Bartke, 2018). In our study design, one example of a relevant individual belief that influences acceptance is concern about the public opinion on subsoil amelioration. Specifically, the "ecologists" have the strongest concerns about the implementation of DLC and have doubts about the societal acceptance of this measure. Some participants pointed out that "invasive" methods such as DLC would be rejected by environmental organizations as well as by the general public. They thus questioned whether farmerswho already face prejudices among the general public-would implement such methods in their fields. Increased yields alone would not compensate for the risk of a lack of societal acceptance. In contrast, the "pioneers" are not concerned that DLC could worsen public opinion about agriculture. Participants mentioned the "marketing" of subsoil amelioration measures as a $\mathrm{CO}_{2}$ sink, i.e., the incorporation and stabilization of carbon in the subsoil, as one way of fostering societal acceptance.

\section{Economic Considerations}

According to Bartkowski and Bartke (2018), economic considerations are the most frequently studied factor related to farmers' behavior. Our results show that economic aspects, such as the utilization options of the alfalfa harvest and the overall cost-benefit ratio, play an important role for the acceptance of subsoil amelioration techniques. Yet, economic factors are not the only decisive factors for farmers and other agricultural stakeholders, and they are not necessarily the most decisive factor. These observations are consistent with the findings of other recent studies on farmers' decision-making regarding soil management (Lastra-Bravo et al., 2015; Bartkowski and Bartke, 2018; Braito et al., 2020; Fantappiè et al., 2020).

With regard to the importance of subsidies, respondents revealed opposing points of view during the focus group discussions. Some favored subsidies for subsoil amelioration measures as an incentive for implementation, whereas others clearly opposed this option. One farmer pointedly expressed his concern, shared by other respondents, that subsidies can prevent a farmer to "really try to find efficient or creative ways" (25) to operate in an economically efficient manner without relying on external financial support. This is in line with Dessart et al. (2019), who summarized that in some cases subsidies may have a negative effect on the intrinsic motivation of farmers.

\section{Farm-Level Considerations}

With regard to farm-level considerations, a homogeneous view emerged across the three perspectives. Our results show that neither farm succession nor the ability to use one's own equipment play an important role in the acceptance of measures such as DLC. However, the "ecologists" are of the opinion that DLC would be more likely to be implemented on owned land than on leased land. This is supported by Viaene et al. (2016), who have shown that farmers who lease land are more reluctant to undertake long-term investments such as the application of compost, as they may not be able to continue farming this land in a few years.

With regard to the cultivation of alfalfa, the farming system seems to play a role as organic farms generally have an advantage in growing alfalfa as they have more experience with the crop. Moreover, the advantage of the alfalfa plant-i.e., that it can supply itself with water from deep soil layers-can also be a disadvantage under certain circumstances. When for example sandy subsoils are not able to store sufficient water, alfalfa will not grow well.

\section{Options to Enhance Acceptance for the DLC Technique}

Regarding the DLC technique, we found that acceptance among the farmers and soil experts interviewed in our survey was mixed; concerns about the technique were present in all three perspectives that have been identified. In particular, our analysis identified a number of barriers for the practical implementation of the DLC technique. This suggests that the design of the technique should be adapted in order to improve its practical feasibility and to increase its attractiveness for farmers.

A specific concern among the respondents was that incorporating compost stripwise into the subsoil is likely to cause a wave formation in the plant stock and consequently lead to heterogeneity in the crop. This runs counter to the farmers' aim of having as homogeneous a crop as possible in the field. Particularly, this could affect the harvesting technique (e.g., threshing) as well as other processes such as application of pesticides, and eventually make it difficult to sell the produce (e.g., due to uneven grain size and quality). Farmers and other soil experts participating in our study see a possible solution in reducing the distances between the furrows that receive treatment. This could contribute to achieving more even effects. Further research could help define ideal spacing for different soil types.

Another potential barrier was seen in the quality and regional availability of compost. The idea of using compost based on 
biological household waste (as tested by Jakobs et al., 2019) was strongly rejected by many participants, as it was thought likely to contain plastic and other contaminants. Certification of compost was seen as an important means for quality assurance, although some respondents questioned whether it could indeed guarantee that compost is plastic-free. Respondents overall expressed a preference of well-rotten compost based on green waste. Another concern conveyed by many respondents was whether sufficient compost was available in their region, as delivering compost over larger distances would cause high transport costs and make DLC unattractive for farmers. Viaene et al. (2016), who explored barriers to compost application on topsoils in Flanders, came to similar conclusions: The authors found that, among other reasons, issues about compost quality, uncertainties about local availability of compost and high transport costs prevented farmers from applying compost on their fields as a soil-improving measure. We conclude that in order to make DLC more acceptable, a careful choice of regionally available composts is key.

Furthermore, our research results deliver clear indications for further research needs from a practical point of view. First, field experiments should investigate the nitrate leaching potential of DLC in detail and it should be ensured that the risk of leaching and endangering of groundwater resources is minimal when the technique is applied properly, particularly with a view on societal acceptance of the measure. Second, the added value of DLC compared to superficial compost application should be verified on test plots.

\section{CONCLUSION}

The results of our acceptance analysis show that while subsoil currently receives little consideration in agricultural practice in Germany, farmers and other relevant stakeholders in the two case study regions are generally aware of the subsoil and the role it can play in climate change adaptation strategies. The respondents regard subsoil amelioration as an effective tool to improve the water storage of the subsoil and thereby to better bridge temporary water deficits. In addition, they acknowledge that subsoil amelioration can mitigate heavy rainfall events, as infiltration and percolation of water in the soil are improved.

We showed that a variety of acceptance factors and barriers can influence the decision to implement biological and mechanical subsoil amelioration techniques. Economic considerations, including a positive cost-benefit ratio, are key for successful implementation of subsoil amelioration. Our analysis has shown that government incentives, including subsidies, might be required to encourage farmers to cultivate alfalfa, for which often no attractive market exists. Appropriate support measures could be integrated into relevant policies, such as regional development programs. Furthermore, a financial reward for carbon storage and sequestration in the subsoil is seen as an additional motivation factor for farmers to implement subsoil amelioration techniques. In addition to economic considerations, individual psychological factors such as awareness of subsoil, environmental awareness, individual norms and beliefs as well as risk perception play an important role. It is important to understand this diversity of influencing factors and to take it into account when designing policy measures that shall promote and support the uptake of subsoil amelioration.

While there was overall consensus that subsoil amelioration can be an effective means for farmers to adapt to climate change, opinions differed on which technique should be applied under which conditions. With regard to technical subsoil amelioration techniques such as DLC, farmers will require assistance in assessing whether their local conditions are suitable for applying the technique. As many regions of the world are facing similar challenges related to changing climate conditions, particularly the increasing frequency and duration of droughts, we believe that subsoil amelioration can be a valuable tool to sustain crop production worldwide. Specific techniques to improve subsoils can be adapted to local conditions and needs.

Our results illustrate that, instead of focusing on one specific technique, it might be more effective to promote a wider range of subsoil amelioration measures that, depending the site conditions and the priorities of the individual farmer, can be applied individually or combined as part of an array of different measures. This include the choice of suitable pre-crops or the choice of available, suitable organic substrates to implement in subsoil layers. Targeted implementation guidelines could be provided through agricultural consultancies and regional chambers of agriculture.

\section{DATA AVAILABILITY STATEMENT}

The raw data supporting the conclusions of this article will be made available by the authors, without undue reservation.

\section{AUTHOR CONTRIBUTIONS}

$\mathrm{MH}$ and ZK designed the concept for the study and developed the Q-set. MH, ZK, HG, and SI planned and conducted workshops, individual interviews, and wrote the paper. $\mathrm{MH}, \mathrm{ZK}$, and SI conducted the analysis. HG took on the role as internal reviewer for quality management. All authors contributed to the article and approved the submitted version.

\section{FUNDING}

This article was prepared as part of the BonaRes research project Sustainable Subsoil Management $\left(\mathrm{Soil}^{3}\right)$ funded by the German Federal Ministry of Education and Research (BMBF), grant number 031B0515F.

\section{ACKNOWLEDGMENTS}

We would like to thank all participants of our study for sharing their views, knowledge, and experiences in the field of soil management. We thank Stefan Engberink for his continuous practical support in this research project. We would also like to thank Sara Bauke, Miriam Athmann, and Oliver Schmittmann for enriching our workshops with their presentations. Finally, we thank McKenna Davis for proofreading and useful advice. 


\section{REFERENCES}

Agovino, M., Casaccia, M., Ciommi, M., Ferrara, M. and Marchesano, K. (2019). Agriculture, climate change and sustainability: the case of EU-28. Ecol. Indicat. 105, 525-43. doi: 10.1016/j.ecolind.2018.04.064

Bampa, F., O'Sullivan, L., Madena, K., Sandén, T., Spiegel, H., Henriksen, C. B., et al. (2019). Harvesting European knowledge on soil functions and land management using multicriteria decision analysis. Soil Use Manage. 35, 6-20. doi: 10.1111 sum. 12506

Bartkowski, B., and Bartke, S. (2018). Leverage points for governing agricultural soils: a review of empirical studies of European farmers' decision-making. Sustainability 10:3179. doi: 10.3390/su10093179

Beillouin, D., Schauberger, B., Bastos, A., Ciais, P., and Makowski, D. (2020). Impact of extreme weather conditions on European crop production in 2018. Phil. Trans. R. Soc. B 375:20190510. doi: 10.1098/rstb.2019.0510

Bindi, M., and Olesen, J. E. (2011). The responses of agriculture in Europe to climate change. Reg. Environ. Change 11, 151-158. doi: $10.1007 / \mathrm{s} 10113-010-0173-\mathrm{x}$

Braito, M., Leonhardt, H., Penker, M., Schauppenlehner-Kloyber, E., Thaler, G., and Flint, C. G. (2020). The plurality of farmers' views on soil management calls for a policy mix. Land Use Policy 99:104876. doi: 10.1016/j.landusepol.2020.104876

Brown, S. R. (1980). Applications of Q-Methodology in Political Science. New Haven, CT; London: Yale University Press.

Brown, S. R. (2006). A match made in heaven: a marginalized methodology for studying the marginalized. Qual. Quant. 40, 361-382. doi: $10.1007 / \mathrm{s} 11135-005-8828-2$

Bumbudsanpharoke, W., Moran, D., and Hall, C. (2009). Exploring perspectives of environmental best management practices in Thai agriculture: an application of Q-methodology. Envir. Conserv. 36, 225-234. doi: $10.1017 /$ S0376892909990397

Byrne, R., Byrne, S., Ryan, R., and O'Regan, B. (2017). Applying the Q-method to identify primary motivation factors and barriers to communities in achieving decarbonisation goals. Energy Policy 110, 40-50. doi: 10.1016/j.enpol.2017.08.007

Cai, H., Ma, W., Zhang, X., Ping, J., Yan, X., Liu, J., et al. (2014). Effect of subsoil tillage depth on nutrient accumulation, root distribution, and grain yield in spring maize. Crop. J. 2, 297-307. doi: 10.1016/j.cj.2014.04.006

Cevallos, G., Grimault, J., and Bellassen, V. (2019). Domestic Carbon Standards in Europe: Overview and Perspectives. I4CE. Available online at: https:// www.i4ce.org/wp-core/wp-content/uploads/2020/02/0218-i4ce3153DomecticCarbonStandards.pdf (accessed 15 March 2021).

Cools, M., Brijs, K., Tormans, H., De Laender, J., and Wets, G. (2012). Optimizing the implementation of policy measures through social acceptance segmentation. Trans. Policy 22, 80-87. doi: 10.1016/j.tranpol.2012. 05.013

Cranfield, J., Henson, S., and Holliday, J. (2010). The motives, benefits, and problems of conversion to organic production. Agric. Hum. Val. 27, 291-306. doi: 10.1007/s10460-009-9222-9

Curry, R., Barry, J., and McClenaghan, A. (2013). Northern Visions? Applying Q methodology to understand stakeholder views on the environmental and resource dimensions of sustainability. J. Environ. Plan. Manage. 56, 624-649. doi: 10.1080/09640568.2012.693453

Dessart, F. J., Barreiro-Hurlé, J., and van Bavel, R. (2019). Behavioural factors affecting the adoption of sustainable farming practices: a policyoriented review. Eur. Rev. Agric. Econ. 46, 417-471. doi: 10.1093/erae/ jbz019

Duong, T. T., Brewer, T., Luck, J., and Zander, K. (2019). A global review of farmers' perceptions of agricultural risks and risk management strategies. Agriculture 9:10. doi: 10.3390/agriculture9010010

Elliott, J., Deryng, D., Müller, C., Frieler, K., Konzmann, M., Gerten, D., et al. (2014). Constraints and potentials of future irrigation water availability on agricultural production under climate change. Proc. Natl. Acad. Sci. U.S.A. 111, 3239-3244. doi: 10.1073/pnas.1222474110

Ellis, G., Barry, J., and Robinson, C. (2007). Many ways to say 'no', different ways to say 'yes': applying Q-methodology to understand public acceptance of wind farm proposals. J. Environ. Plan. Manage. 50, 517-551. doi: $10.1080 / 09640560701402075$
Eory, V., Pellerin, S., Garcia, G. C., Lehtonen, H., Licite, I., Mattila, H., et al. (2018). Marginal abatement cost curves for agricultural climate policy: stateof-the art, lessons learnt and future potential. J. Clean. Product. 182, 705-716. doi: 10.1016/j.jclepro.2018.01.252

European Commission (2020). Special Eurobarometer 504: Europeans, Agriculture and the CAP. Field Work August 2020 - September 2020. (Study concucted by Kantar). European Commission.

Fairweather, J. R. (1999). Understanding how farmers choose between organic and conventional production: results from New Zealand and policy implications. Agric. Hum. Val. 16, 51-63. doi: 10.1023/A:1007522819471

Fantappiè, M., Lorenzetti, R., De Meo, I., and Costantini, E. A. C. (2020). How to improve the adoption of soil conservation practices? Suggestions from farmers' perception in western Sicily. J. Rural Stud. 73, 186-202. doi: 10.1016/j.jrurstud.2019.11.001

Flaten, O. G., Lien, M., Koesling, Valle, P. S., and Ebbesvik, M. (2005). Comparing risk perceptions and risk management in organic and conventional dairy farming: empirical results from Norway. Livestock Product. Sci. 95, 11-25. doi: 10.1016/j.livprodsci.2004.10.014

Frelih-Larsen, A., Hinzmann, M., and Ittner, S. (2018). The 'invisible' subsoil: an exploratory view of societal acceptance of subsoil management in Germany. Sustainability 10:3006. doi: 10.3390/su10093006

Gaiser, T., Perkons, U., Küpper, P. M., Puschmann, D. U., Peth, S., Kautz, T., et al. (2012). Evidence of improved water uptake from subsoil by spring wheat following lucerne in a temperate humid climate. Field Crops Res. 126, 56-62. doi: 10.1016/j.fcr.2011.09.019

Ghadim, A. K. A., Pannell, D. J., and Burton, M. P. (2005). Risk, uncertainty, and learning in adoption of a crop innovation. Agric. Econ. 33, 1-9. doi: 10.1111/j.1574-0862.2005.00433.x

Gill, J. S., Sale, P. W. G., and Tang, C. (2008). Amelioration of dense sodic subsoil using organic amendments increases wheat yield more than using gypsum in a high rainfall zone of southern Australia. Field Crops Res. 107, 265-275. doi: $10.1016 /$ j.fcr.2008.02.014

Grillakis, M. G. (2019). Increase in severe and extreme soil moisture droughts for Europe under climate change. Sci. Total Environ. 660, 1245-1255. doi: 10.1016/j.scitotenv.2019.01.001

Hagedorn, F., and Bundt, M. (2002). The age of preferential flow paths. Geoderma 108, 119-132. doi: 10.1016/S0016-7061(02)00129-5

Hasan, M. K., and Kumar, L. (2019). Comparison between meteorological data and farmer perceptions of climate change and vulnerability in relation to adaptation. J. Environ. Manage. 237, 54-62. doi: 10.1016/j.jenvman.2019.02.028

Helming, K., Daedlow, K., Paul, C., Techen, A.-K., Bartke, S., Bartkowski, B., et al. (2018). Managing soil functions for a sustainable bioeconomyassessment framework and state of the art. Land Degrad. Dev. 29, 3112-3126. doi: 10.1002/ldr.3066

Hermann, D., Sauthoff, S., and Mußhoff, O. (2017). Ex-ante evaluation of policy measures to enhance carbon sequestration in agricultural soils. Ecol. Econ. 140, 241-250. doi: 10.1016/j.ecolecon.2017.05.018

Howden, S. M., Soussana, J.-F., Tubiello, F. N., Chhetri, N., Dunlop, M. and Meinke, H. (2007). Adapting agriculture to climate change. Proc. Natl. Acad. Sci. U.S.A. 104, 19691-19696. doi: 10.1073/pnas.0701890104

Huang, N., Athmann, M., and Han, E. (2020). Biopore-induced deep root traits of two winter crops. Agriculture 10:634. doi: 10.3390/agriculture10120634

Iglesias, A., and Garrote, L. (2015). Adaptation strategies for agricultural water management under climate change in Europe. Agric. Water Manage. 155, 113-124. doi: 10.1016/j.agwat.2015.03.014

Iglesias, A., Garrote, L., Diz, A., Schlickenrieder, J., and Martin-Carrasco, F. (2011). Re-thinking water policy priorities in the Mediterranean region in view of climate change. Environ. Sci. Policy 14, 744-757. doi: 10.1016/j.envsci.2011.02.007

Iglesias, A., Quiroga, S., Moneo, M., and Garrote, L. (2012). From climate change impacts to the development of adaptation strategies: challenges for agriculture in Europe. Clim. Change 112, 143-168. doi: 10.1007/s10584-011-0344-x

IPCC (2019). Special Report on Climate Change, Desertification, Land Degradation, Sustainable Land Management, Food Security, and Greenhouse gas fluxes in Terrestrial Ecosystems. IPCC.

Ittner, S., Gerdes, H., Athmann, M., Bauke, S., Gocke, M., Guigue, J., et al. (2020). The impact of subsoil management on the delivery of ecosystem services. BonaRes Ser. doi: 10.20387/BONARES-BSZH-QBKN 
Jacobs, A., Heidecke, C., and Jumshudzade, Z. (2020). Soil organic carbon certificates - potential and limitations for private and public climate action. Landbauforschung 70, 31-35. doi: 10.3220/LBF1605778405000

Jakobs, I., Schmittmann, O., Athmann, M., Kautz, T., and Lammers, P. S. (2019). Cereal response to deep tillage and incorporated organic fertilizer. Agronomy 9:296. doi: 10.3390/agronomy9060296

Kamal, S., Kocór, M., and Grodzińska-Jurczak, M. (2014). Quantifying human subjectivity using Q method: when quality meets quantity. Qual. Sociol. Rev. 3, 61-79.

Kautz, T., Amelung, W., Ewert, F., Gaiser, T., Horn, R., Jahn, R., et al. (2013). Nutrient acquisition from arable subsoils in temperate climates: a review. Soil Biol. Biochem. 57, 1003-1022. doi: 10.1016/j.soilbio.2012.09.014

Kautz, T., Athmann, M., and Köpke, U. (2014). "Growth of barley (Hordeum vulgare L.) roots in biopores with differing carbon and nitrogen contents," in Building Organic Bridges, Thuenen Report. Braunschweig: Johann Heinrich von Thünen-Institut, 391-394.

Kuzyakov, Y., and Blagodatskaya, E. (2015). Microbial hotspots and hot moments in soil: concept \& review. Soil Biol. Biochem. 83, 184-199. doi: 10.1016/j.soilbio.2015.01.025

Landl, M., Schnepf, A., Vereecken, H., and Vanderborght, J. (2019). Modeling the impact of biopores on root growth and root water uptake. Vadose Zone J. 8, 1-20. doi: 10.2136/vzj2018.11.0196

Lastra-Bravo, X. B., Hubbard, C., Garrod, G., and Tolón-Becerra, A. (2015). What drives farmers' participation in EU agri-environmental schemes?: results from a qualitative meta-analysis. Environ. Sci. Policy 54, 1-9. doi: 10.1016/j.envsci.2015.06.002

Leinonen, I., Eory, V., MacLeod, M., Sykes, A., Glenk, K., and Rees, B. (2019). Comparative Analysis of Farm-Based Carbon Audits. Available online at: https://www.climatexchange.org.uk/research/projects/comparativeanalysis-of-farmbased-carbon-audits/ (accessed 15 March 2021).

Leskiw, L. A., Welsh, C. M., and Zeleke, T. B. (2012). Effect of subsoiling and injection of pelletized organic matter on soil quality and productivity. Can. J. Soil. Sci. 92, 269-276. doi: 10.4141/cjss2011-003

Lynch, J. P., and Wojciechowski, T. (2015). Opportunities and challenges in the subsoil: pathways to deeper rooted crops. J. Exp. Bot. 66, 2199-2210. doi: $10.1093 / \mathrm{jxb} /$ eru508

Marr, E. J., and Howley, P. (2019). The accidental environmentalists: factors affecting farmers' adoption of pro-environmental activities in England and Ontario. J. Rural Stud. 68, 100-111. doi: 10.1016/j.jrurstud.2019.01.013

Mills, J., Gaskell, P., Ingram, J., Dwyer, J., Reed, M., and Short, C. (2017). Engaging farmers in environmental management through a better understanding of behaviour. Agric. Hum. Val. 34, 283-299. doi: 10.1007/s10460-016-9705-4

Mitter, H., Larcher, M., Schönhart, M., Stöttinger, M., and Schmid, E. (2019). Exploring farmers climate change perceptions and adaptation intentions: empirical evidence from Austria. Environ. Manage. 63, 804-821. doi: $10.1007 / \mathrm{s} 00267-019-01158-7$

Müller, F. H., and Kals, E. (2004). Die Q-Methode. Ein innovatives Verfahren zur Erhebung subjektiver Einstellungen und Meinungen. Forum: qualitative Sozialforschung, Berlin, 5.

Pe’er, G., Lakner, S., Seppelt, R., Bezák, P., Bonn, A., Concepción, E. D., et al. (2020). The EU's Common Agriculture Policy and Sustainable Farming: A Statement by Scientists. Geneva: Zenodo - an OPEN AIRE project. doi: 10.5281/ZENODO.4311314

Pe’er, G., Zinngrebe, Y., Moreira, F., Sirami, C., Schindler, S., Müller, R., et al. (2019). A greener path for the EU Common Agricultural Policy. Science 365, 449-451. doi: 10.1126/science.aax3146

Petrescu-Mag, R. M., Petrescu, D. C., and Azadi, H. (2020). A social perspective on soil functions and quality improvement: Romanian farmers' perceptions. Geoderma 380:114573. doi: 10.1016/j.geoderma.2020.114573

Prager, K., and Curfs, M. (2016). Using mental models to understand soil management. Soil Use Manage. 32, 36-44. doi: 10.1111/sum.12244

Prager, K., and Posthumus, H. (2010). "Socio-economic factors influencing farmers' adoption of soil conservation practices in Europe," in Human Dimensions of Soil and Water Conservation: A Global Perspective, Agriculture Issues and Policies, ed T. L. Napier (New York, NY: Nova Science Publishers), 203-223.

Ricart, S., Olcina, J., and Rico, A. (2018). Evaluating public attitudes and farmers' beliefs towards climate change adaptation: awareness, perception, and populism at European level. Land 8:4. doi: 10.3390/land80 10004

Riediger, J., Breckling, B., Nuske, R. S., and Schröder, W. (2014). Will climate change increase irrigation requirements in agriculture of central Europe? A simulation study for Northern Germany. Environ. Sci. Eur. 26:18. doi: 10.1186/s12302-014-0018-1

Sale, P. W., Gill, J. S., Peries, R. R., and Tang, C. (2019). Crop responses to subsoil manuring. I. Results in south-western Victoria from 2009 to 2012. Crop Pasture Sci. 70:44. doi: 10.1071/CP18115

Sattler, C., and Nagel, U. J. (2010). Factors affecting farmers' acceptance of conservation measures-a case study from north-eastern Germany. Land Use Policy 27, 70-77. doi: 10.1016/j.landusepol.2008. 02.002

Schneider, F., and Don, A. (2019a). Root-restricting layers in German agricultural soils. Part I: extent and cause. Plant Soil 442, 433-451. doi: 10.1007/s11104-019-04185-9

Schneider, F., and Don, A. (2019b). Root-restricting layers in German agricultural soils. Part II: adaptation and melioration strategies. Plant Soil 442, 419-432. doi: 10.1007/s11104-019-04186-8

Seidel, S. J., Gaiser, T., Kautz, T., Bauke, S. L., Amelung, W., Barfus, K., et al. (2019). Estimation of the impact of precrops and climate variability on soil depth-differentiated spring wheat growth and water, nitrogen and phosphorus uptake. Soil Tillage Res. 195:104427. doi: 10.1016/j.still.2019. 104427

Spinoni, J., Vogt, J. V., Naumann, G., Barbosa, P., and Dosio, A. (2018). Will drought events become more frequent and severe in Europe?: future drought events in Europe. Int. J. Climatol. 38, 1718-1736. doi: 10.1002/ joc.5291

Stainton Roger, R. (1995). "Q methodology," in Rethinking Methods in Psychology, eds J. A. Smith, R. Harré, and L. Van Langenhofe (London; Thousand Oaks, CA: Sage Publications), 178-193.

Sulewski, P., Was, A., Kobus, P., Pogodzińska, K., Szymańska, M., and Sosulski, T. (2020). "Farmers' attitudes towards risk-an empirical study from Poland. Agronomy 10:1555. doi: 10.3390/agronomy10101555

Toreti, A., Belward, A., Perez-Dominguez, I., Naumann, G., Luterbacher, J., Cronie, O., et al. (2019). The exceptional 2018 European water seesaw calls for action on adaptation. Earths Future 7, 652-663. doi: 10.1029/2019EF00 1170

Trujillo-Barrera, A., Pennings, J. M. E., and Hofenk, D. (2016). Understanding producers' motives for adopting sustainable practices: the role of expected rewards, risk perception and risk tolerance. Eur. Rev. Agric. Econ. 43, 359-382. doi: 10.1093/erae/jbv038

Viaene, J., Van Lancker, J., Vandecasteele, B., Willekens, K., Bijttebier, J., Ruysschaert, G., et al. (2016). Opportunities and barriers to on-farm composting and compost application: a case study from northwestern Europe. Waste Manage. 48, 181-192. doi: 10.1016/j.wasman.2015. 09.021

Watts, S., and Stenner, P. (2005). "Doing Q methodology: theory, method and interpretation," in Qualitative Research in Psychology, ed D. Giles (Edward Arnold Ltd.), 67-91.

Webler, T., Danielson, S., and Tuler, S. (2009). Using Q Method to Reveal Social Perspectives in Environmental Research. Greenfield MA: Social and Environmental Research Institute.

Wiesmeier, M., Mayer, S., Paul, C., Helming, K., Don, A., Franko, U., et al. (2020). $\mathrm{CO}_{2}$ certificates for carbon sequestration in soils: methods, management practices and limitations. BonaRes Seri. doi: 10.20387/BONARES-NE 0G-CE98

Williams, A., Hunter, M. C., Kammerer, M., Kane, D. A., Jordan, N. R., Mortensen, D. A., et al. (2016). Soil water holding capacity mitigates downside risk and volatility in US Rainfed Maize: time to invest in soil organic matter? PLoS ONE 11:e0160974. doi: 10.1371/journal.pone.0160974

Woods, B. A., Nielsen, H. O., Branth Pedersen, A., and Kristofersson, D. (2017). Farmers' perceptions of climate change and their likely responses in Danish agriculture. Land Use Policy 65, 109-120. doi: 10.1016/j.landusepol.2017. 04.007

Yunusa, I. A. M., and Newton, P. J. (2003). Plants for amelioration of subsoil constraints and hydrological control: the primer-plant concept. Plant Soil 257, 261-281. doi: 10.1023/A:1027381329549 
Zhang, B., Horn, R., and Hallett, P. D. (2005). Mechanical resilience of degraded soil amended with organic matter. Soil Sci. Soc. Am. J. 69, 864-871. doi: $10.2136 /$ sssaj2003.0256

Conflict of Interest: The authors declare that the research was conducted in the absence of any commercial or financial relationships that could be construed as a potential conflict of interest.
Copyright (C) 2021 Hinzmann, Ittner, Kiresiewa and Gerdes. This is an open-access article distributed under the terms of the Creative Commons Attribution License (CC $B Y)$. The use, distribution or reproduction in other forums is permitted, provided the original author(s) and the copyright owner(s) are credited and that the original publication in this journal is cited, in accordance with accepted academic practice. No use, distribution or reproduction is permitted which does not comply with these terms. 